\title{
The Sociopsychological Profile of Persons with Alcohol Anosognosia in the Context of Social Customer Support
}

\author{
Konstantin Khvostunov*, Raisat Adzhimuradova, Elena Egorova, Olga Lazareva, Svetlana Kazakova, Marina Volkova \\ Department of Nursing Management and Social Work, I.M. Sechenov First Moscow State Medical University (Sechenov \\ University), Moscow, Russian Federation
}

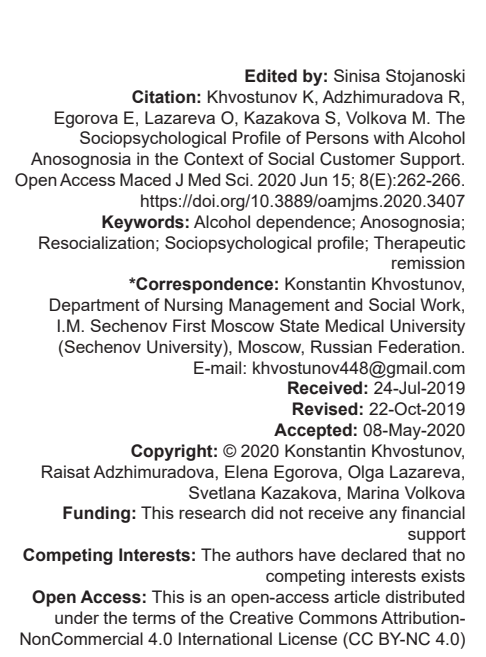

Abstract

AIM: We aimed to focus on the sociopsychological profile of a person with alcohol anosognosia

METHODS: The study was conducted in the narcological inpatient adult department of the Starooskolsky Narcological Dispensary for 1.5 months and involved 60 male patients over the age of 18 with at least 5 -year alcohol dependence.

RESULTS: As a result of the study, the individual typological features of patients with anosognosia were identified and structured.

CONCLUSION: The findings may be applied in the development of social support measures for persons with anosognosia to resocialize them and achieve long-term therapeutic remission.

\section{Introduction}

Alcohol dependence is central to the structure of drug-related diseases and is recognized as one of the urgent problems of public health and society. Its medical and social significance is associated with a high level of disease prevalence (the number of registered people with alcohol dependence is about $2 \%$ of the total population in the Russian Federation), interconnected criminogenic factors, as well as negative consequences of the disease for the health and social status of patients and their immediate environment [1]. According to foreign studies conducted by National Development and Research Institutes, up to $64 \%$ of people with alcohol dependence also abuse other psychoactive substances [1], [2].

There are a lot of modern studies conducted to study medical, social, and psychological sides of alcoholism as a complex problem that demands adequate solutions. The most frequent are studies about alcoholism among adolescents [3], [4], [5], [6], [7], impact of alcoholism on family relationships from the sides of men and women [8], [9], [10]. There are different points of scientists' attention concerning alcoholism as a complex problem. Moreover, there are multiple attitudes concerning where the problem of alcoholism starts, from what doze and frequency of taking alcohol. Hence, all the scientists are unified as for the position that alcohol is destructive for psyche at any age [11], [12], [13]. Anosognosia is a mental illness, the carrier of which is a person who is unaware of his own mental health condition, i.e. is not obviosity and no any wish or willpower to acknowledge dependence on alcohol. The sick with alcohol anosognosia because of mental problem, caused by strong alcohol dependence, cannot perceive their condition accurately. The psychological causes of the problem of anosognosia, more or less attention to its relation with dipsomania and its treatment, are considered in the works of modern scientists such as Vannini et al. [14], Yakovlev et al. [15], Steinmetz et al. [16], Tarkhan et al. [17], Walvoort et al. [18], Skrypnikov et al. [19], Sullivan and Pfefferbaum [20], Fama [21], and Gerridzen et al. [22].

At present, there is a tendency toward a more holistic scientific approach to the study of the problem of alcoholism. From this perspective, traditional clinical and biological views are complemented by psychological concepts of alcohol dependence 
development, which highlight the personal factors and mechanisms of alcohol abuse, addiction formation and therapeutic resistance, as well as the conditions for overcoming them in the treatment and rehabilitation process [23], [24], [25]. Rehabilitation is considered not only as a process of patients' physical and psychosocial recovery but also as a special integrative approach to them, taking into account the specifics of the system of their significant relationships, and, above all, attitudes toward the disease and treatment [26].

As known, the person's ability to critically assess his/her condition is regarded as an indicator of the normal course of mental processes. The alcohol addict's lack of a critical attitude toward his/her condition and disease, followed by an unwillingness to undergo treatment and live soberly, should be viewed as alcohol anosognosia - one of the main psychopathological phenomena in chronic alcoholism, which defines its assessment as a mental illness. Alcohol anosognosia is understood as the patient's persistent belief that he/she does not have chronic alcoholism. It is assumed that the patient, with regard to his/her education, upbringing, constantly flowing information about the consequences of alcohol abuse, as well as personal experience, should know that he/she has alcohol addiction. This circumstance is especially important since otherwise the insufficient knowledge or inadequate perceptions of this disease could be decisive in denying it [22]. Alcohol anosognosia can be considered as a psychological defense mechanism, as a blockade or distortion of experiences associated with the disease to eliminate the conflict between the "self-concept" and direct experience, as a result of a widespread positive attitude toward alcohol consumption with a negative attitude toward its consequences.

The label of an alcoholic obviously has its own value and negative content. In these cases, anosognosia helps the person to maintain his/her social status. Overcoming this disease is associated with a change in attitude toward the individual self, as well as with trauma to the entire personality structure. The inclusion of psychological protective mechanisms at this stage of alcoholism is carried out on a subconscious level and does not depend on the willpower of the person himself/ herself [27], [28].

The purpose of this study was to identify the sociopsychological profile of a person with alcohol anosognosia for the further development of measures to resocialize such clients and draw up an individual rehabilitation plan.

\section{Materials and Methods}

The study was conducted in the narcological inpatient adult department of the Starooskolsky Narcological Dispensary for 1.5 months and involved
60 male patients over the age of 18 . The criterion for selection was alcohol dependence for at least 5 years.

To obtain empirical data, the questionnaire "Alcohol Anosognosia" (by Rybakova et al. [23], [24] and Bocharov and Ilyuk [25]) and the Freiburgh personality inventory (FPI) multifactor personality test [26] were used.

The questionnaire "Alcohol Anosognosia" (by Rybakova et al. [23], [24]) was tested during the examination of 106 patients who were hospitalized with a diagnosis of alcohol dependence (F10.2 according to ICD10). Their average age was $42.1 \pm 8.8$ years, the duration of dependence was $11.3 \pm 7.0$ years. The structure of the questionnaire, consisting of 7 subscales, was determined: Lack of information, non-recognition of the symptoms of the disease, non-recognition of the disease as a whole, non-recognition of the consequences of the disease, emotional rejection of the disease, disagreement with treatment, and rejection of sobriety. The psychometric characteristics of the instrument (external criterion validity, reliability test retest, and internal consistency) were investigated and the questionnaire was standardized. The average empirical values of the subscale were determined. Hence, the applied questionnaire "Alcohol Anosognosia" allows to get a comprehensive assessment of the level of anosognosia for its individual components, as well as presents a profile of alcoholic anosognosia.

Before filling out the questionnaire "Alcohol Anosognosia," all the patients were informed about the purpose of the study. The time taken to complete the questionnaire was not limited, being on average 25-30 min. The study was conducted simultaneously with several subjects, who in the process of filling out forms did not talk to each other.

The study of the individual typological features of a person with alcohol anosognosia for the construction of a sociopsychological profile was conducted using the FPI multifactor personality test.

In accordance with the ICD-10, all the respondents were diagnosed with alcohol-related disorders F 10.2. Before taking part in the study, the patients gave their written consent. The full confidentiality of personal data was guaranteed. The survey was conducted according to selected methods. The study used standard test paper forms as well as automated systems that allow processing the obtained results using a computer. The program "Microsoft Office Excel" was used for statistical data processing.

The sociodemographic composition of patients participating in the study is characterized by the following indicators: $18-30$ years: 20\%, 31-45 years: $45 \%, 46-50$ years: $25 \%$, and over 50 years: $5 \%$. About half of the respondents have families. Marital status of the respondents is as follows: $50 \%$ - divorced; $25 \%$ married; $20 \%$ - single; and 5\% - widowers. Almost twothirds of the respondents $(65 \%)$ have children.

More than half of the respondents $(60 \%)$ have secondary vocational education, another third (30\%) 
have higher education, and $10 \%$ - incomplete secondary education. The share of workers accounted for $10 \%$ (6 persons out of 60) of the total number of patients studied.

\section{Results and Discussion}

When assessing the level of alcohol anosognosia in patients surveyed, the highest indicators were observed on the following scales: Denial of the disease, disagreement with treatment, lack of awareness, and non-acceptance of sobriety.

The average indicators of the lack of awareness were $85 \%$ of all patients tested. The most common is the belief that alcoholism is a manifestation of weakness, rather than an independent disease. Almost all the patients are convinced that if they do not drink alcohol for some time, they will be able to control the dose of alcohol taken. The proportion of such patients accounted for $95 \%$. At the same time, these patients consider alcoholism a disease, and $75 \%$ of them deny that they have it. As can be seen, two opposite beliefs are formed simultaneously. About $20 \%$ of respondents do not consider craving and drinking the next day after alcohol consumption a sign of alcoholism, but $80 \%$ expressed uncertainty about the correctness of such behavior.

About $10 \%$ of patients denied symptoms of the disease, which indicates an average level of anosognosia. They recognized only two main symptoms of alcohol dependence: Loss of control over alcohol consumption and alcohol withdrawal.

The subscale "Denial of the disease" has two levels, reflecting the absence or presence of anosognosia. Every third patient gave answers corresponding to the presence of anosognosia. The patients indicated that someone from their relatives insisted on their treatment, and they did not understand why they were in a narcological dispensary. There was no intrinsic motivation.

About $70 \%$ of patients did not recognize the consequences of the disease, while they recognized the deterioration of mental and physical health due to alcohol intake. About 90\% acknowledged that their family relations deteriorated due to alcohol consumption. About $40 \%$ of patients confirmed that under the influence of alcohol, they could commit acts that in a sober state are unacceptable to them.

The results of the subscale "emotional nonacceptance of the disease" reflected the patients' low concern about their own treatment for alcoholism. About $70 \%$ of those who completed the questionnaire failed to accept the fact of the disease.

About $90 \%$ of respondents expressed disagreement with treatment, which corresponds to a significant level of anosognosia. While they do not agree that they should be treated for alcoholism, they believe that they just need help to stop and remove physiological discomfort, and after that, they will be completely healthy because they are not alcoholics. They perceive inpatient treatment as a solution to their problems at work, at home, or in society.

On the subscale "non-acceptance of sobriety," $80 \%$ of respondents believe that they undergo treatment to "improve" their health so that they could continue drinking alcohol. However, after treatment, in their opinion, they will be able to control the amount of alcohol consumed.

When determining the priority personality traits of patients with alcoholic anosognosia, high neuroticism, psychosomatic disorders, aggressiveness, sociability, and emotional lability were revealed. The respondents had emotional instability, increased excitability, insufficient self-regulation, and protection of mental activity, mainly of the male type.

The "neuroticism" Scale I indicator in 75\% of respondents was at a high level, which indicates a pronounced neurotic syndrome in patients with chronic alcoholism. They are susceptible to psychosomatic disorders, but at the same time, their appearance and behavior are characterized by vigor, a surge of energy and improved health, which can be explained by the fact that they were in the hospital, and some medical rehabilitation measures were taken.

The evaluation of the results on the Scale II (spontaneous aggressiveness) showed a high level in $85 \%$ of respondents, which makes it possible to conclude that patients with alcohol anosognosia are characterized by a high level of pathology manifestation. Their behavior is impulsive, which prevents them from creating social comfort for themselves and indicates poor self-control.

On the Scale III (depressiveness), the majority of patients gave answers in the range corresponding to an average level, which makes it possible to diagnose the signs of the psychopathological depressive syndrome. However, the answers were heterogeneous; $15 \%$ of respondents showed results corresponding to a low level of depression, $45 \%$ - an average level, and $40 \%$ - a high level. The results can be explained by the patients' abrupt mood swings during the study and quite insincere answers. Much in the results' assessment depended on the period of treatment and hospital stay. At the initial stage of treatment, the patients gave answers implying a higher level of depression.

On the Scale IV (irritability), the indicators were within the limits of high values and accounted for $90 \%$, which indicates reduced emotional stability and lack of selfregulation. Such patients are not capable of work requiring a certain mental strain and high concentration. Performing a group task often leads to conflicts within the group.

The results of processing the answers on the Scale $V$ (sociability) showed that $85 \%$ of respondents demonstrated a pronounced need for communication and constant readiness to meet this need. 
On the Scale VI (tranquility), all the patients gave answers corresponding to a low level. As evidenced by the poor protection from the stressors of ordinary life situations, they are in a state of maladaptation, anxiety, and loss of control over craving for alcohol. Even while undergoing treatment, they think about alcohol and look for a way to get it and drink unnoticed, for example, to improve sleep.

On the Scale VII (reactive aggressiveness), almost equivalent results were obtained at all levels, which generally indicates the pronounced signs of pathology manifestation of an extractive type. Such feelings as pride, duty, love, shame, etc., have low significance for patients, while their physiological needs are strengthened.

On the Scale VIII (shyness), 85\% of answers corresponded to a low level. In the hospital, patients are brave and decisive enough; they do not know how to wait patiently. In the group and in individual conversations, they stay at ease, independently, even somewhat impudent, take liberties, and like to interfere in everything and always be in the public eye.

On the Scale IX (openness), $80 \%$ of patients showed a low level, which makes it possible to indicate their distrustful attitude toward the social environment. In this case, the reliability of the results can be questioned since the patients hardly showed an adequate response to the study.

On the Scale $X$ (extraversion-introversion), the results corresponded to an average level in $60 \%$ and a low level in $40 \%$. This testifies to the difficulties in making contact in a sober state.

On the Scale XI (emotional lability), all the patients gave answers corresponding to a high level. They are characterized by emotional instability, frequent mood swings, and increased excitability and irritability, which is associated with the state of maladaptation and anxiety related to the disorganization of habitual behavior.

The Scale XII (masculinity-femininity) showed the mental activity of the male type in all the patients.

Thus, the respondents do not know how and/ or do not wish to restrain their temper in society and require the immediate satisfaction of their desires. The need for stimulation and exciting situations leads to an urge to satisfy their desires through alcohol intake. At the first contact, the patients were talkative; they willingly agreed to participate in the study. However, the study itself, which in their opinion was long and tedious, made them irritable and willing to give up. The patients said: "I deliberately did not answer the questions correctly, so I was labeled as an alcoholic;" "I tried to answer just as my wife (mother) would want me to" and others. For example, most respondents drink alcohol as a sedative and do not understand the origin of their alcoholism.

The main concern on the subscale of the lack of awareness was the belief that alcoholism is not a disease, and there is a way to learn how to dose alcohol intake. The majority of alcohol-dependent patients (90\%) did not recognize themselves as patients suffering from alcoholism; they believed that their relatives and doctors exaggerate the dependence on alcohol. The patients easily agreed with their concern about the drug-related illness and its consequences, but at the same time, they were discontented with the fact that their relatives recognized their alcohol dependence and demanded that they give up drinking. Therefore, the patients showed typical for alcohol anosognosia doubts about the need and advisability of drug treatment.

\section{Conclusions}

As a result of the study, it was found that patients with alcohol anosognosia have the following individual and typological features as increased emotional lability, low level of self-control, dominance of physiological needs, presence of depressive symptoms, high level of neuroticism and anxiety, low level of trust in medical personnel and relatives, presence of a pronounced need for communication, and denial of alcohol dependence or its underestimation.

The study made it possible to form a typical sociopsychological profile of males with alcohol anosognosia, who have been alcohol dependent for at least 5 years and undergoing rehabilitation in a narcological hospital. The identified personality features must be considered when developing social support measures for such clients to resocialize them and achieve long-term therapeutic remission.

\section{References}

1. Koshkina EA. Medical, Social and Economic Consequences of Drug and Alcohol Addiction. New York: PER SE; 2008. p. 112-282.

2. Chirko VV, Demina MV. Essays on Clinical Narcology. Moscow: Medpraktika; 2002

3. Balakrishnan P. A comparative study to assess the knowledge and attitude of adolescents (16-18 years) regarding alcoholism and its hazards between selected rural and urban pre-university college at Bangalore. Asian J Nurs Educ Res. 2011;1(1):31-6.

4. Paul L, Ramya KR. Knowledge and attitude towards alcoholism among adolescents. Asian J Nurs Educ Res. 2012;2(4):212-4.

5. Shambhavi SS, D'Souza VM. Assess the Knowledge of Adolescents Regarding Alcoholism and Its Effects in a Selected Urban School at Mangalore with a View to Prepare a Pamphlet. Asian J Nurs Educ Res. 2015;5(1):23-25. https://doi. org/10.5958/2349-2996.2015.00006.3

6. Mendagudli VG, Vijayalakshmi K. A descriptive study on attitude and practice towards alcoholism among adolescents. Int J Adv Nurs Manage. 2017;5(1):59-64. https://doi. org/10.5958/2454-2652.2017.00013.0

7. Ramalakshmi G. A study to assess the level of knowledge 
regarding alcoholism among adolescent in Banjarwala, Dehradun. Int J Adv Nurs Manage. 2018;6(1):50-6. https://doi. org/10.5958/2454-2652.2018.00012.4

8. Sasi M. Knowledge on ill effects of alcoholism and the attitude towards alcoholic husbands as perceived by wives. Int J Nurs Educ Res. 2015;3(4):339-43. https://doi. org/10.5958/2454-2660.2015.00020.4

9. Ramya KR, Paul SL. Psychosocial problems of wives of alcoholics. Asian J Nurs Educ Res. 2013;3(1):29-30.

10. Shaydukova LK, Giliazeva GA. Peculiarities of psychotherapy of single and married women, who abuse alcohol, with depressive disorders: Work with subpersonal "targets". Narcology. 2018;17(1):40-7.

11. Kumar JV, Francis RA. The causes, consequences, types of alcoholism and role of supervisor for alcoholic labourers in workplace-an overview. Res J Hum Soc Sci. 2018;9(1):35-39. https://doi.org/10.5958/2321-5828.2018.00007.4

12. Srinivasan M. Psychological distress among spouses of alcoholic menin rural Uttarakhand.Asian JNurs EducRes. 2015;5(4):483-6. https://doi.org/10.5958/2349-2996.2015.00099.3

13. Hegade KN, Nandagaon V. The effectiveness of structured teaching programme on knowledge regarding ill effects of alcoholism among auto-rickshaw drivers. Asian J Nurs Educ Res. 2016;6(1):53-60. https://doi. org/10.5958/2349-2996.2016.00011.2

14. Vannini P, Hanseeuw B, Munro CE, Amariglio RE, Marshall GA, Rentz DM, et al. Anosognosia for memory deficits in mild cognitive impairment: Insight into the neural mechanism using functional and molecular imaging. Neuroimage Clin. 2017;15:408-14. https://doi.org/10.1016/j.nicl.2017.05.020 PMid:28616381

15. Yakovlev AA, Dyachkov AG, Musatov VB, Aizsilnieks OV, Strelyanaya EV, Avdoshina DD. Evaluation of an adhesion of antiretroviral therapy in HIV-infected patients using alcohol. J Infektol. 2018;10(1):29-35.

16. Steinmetz J, Theisen-Flies C, Federspiel C. Views on quality of life differ between alcohol related brain damaged individuals and their healthcare professionals. Appl Res Qual Life. 2016;11:239-51. https://doi.org/10.1007/s11482-014-9365-8

17. Tarkhan AU, Nezhdanov GA, Zubova EY, Popov YV, Chekhlaty El, Neznanov NG, et al. Functional asymmetry of the brain and clinical features of alcoholism. Res Psychoneurol Inst. 2016;48(1):42-52.

18. Walvoort SJ, van der Heijden PT, Kessels RP, Egger JI. Measuring illness insight in patients with alcohol-related cognitive dysfunction using the Q8 questionnaire: A validation study. Neuropsychiatr Dis Treat. 2016;12:1609-15. https://doi. org/10.2147/ndt.s104442

PMid:27445476
19. Skrypnikov AM, Zhyvotovska LV, Herasymenko LO, Boiko DI. Alexithymia in healthy people and its role in development of different disorders. Med Ecol Probl. 2019;23(1-2):30-33. https:// doi.org/10.31718/mep.2019.23.1-2.07

20. Sullivan EV, Pfefferbaum A. Brain-behavior relations and effects of aging and common comorbidities in alcohol use disorder: A review. Neuropsychology. 2019;33(6):760-80. https://doi.org/10.1037/neu0000557

PMid:31448945

21. Fama R. Introduction to the special section on alcohol: Review of cognitive, emotional, and neural deficits and recovery with sustained abstinence and treatment. Neuropsychology. 2019;33(6):757-9. https://doi.org/10.1037/neu0000588 PMid:31448944

22. Gerridzen IJ, Joling KJ, Depla MF, Veenhuizen RB, Verschuur EM, Twisk JW, et al. Awareness and its relationships with neuropsychiatric symptoms in people with Korsakoff syndrome or other alcohol-related cognitive disorders living in specialized nursing homes. Int $\mathrm{J}$ Geriatr Psychiatry. 2019;34(6):836-45. https://doi.org/10.1002/gps.5093

PMid:30854733

23. Rybakova YV, llyuk RD, Krupitsky EM, Bocharov VV, Vuks AY Methods for assessing anosognosia in patients with alcoholism: Guidelines. J Neurol Psychiatry Alcohol. 2011;1(2):30-8.

24. Rybakova YV. Alcoholic Anosognosia: Assessment Technique and Relationship with Clinical and Psychosocial Characteristics of Patients. Author's PhD dissertation. St. Petersburg: Bekhterev Psychoneurological Research Institute; 2012. https:// doi.org/10.14529/psy170104

25. Bocharov VV, llyuk RD, Rybakova YV, Krupitsky EM. Methodology for Assessing Anosognosia in Patients with Alcoholism. St. Petersburg: Methodological Guidelines; 2011. Available form: http://www.padabum.com/d.php?id=106240. [Last accessed on 2019 Jul 05].

26. Fahrenberg J, Hampel R, Selg H. Freiburg Personality Inventory FPI-R. Primary Data from the Standardization Sample 1982. (Version 1). Trier: Center for Research Data in Psychology, PsychData of the Leibniz Institute for Psychology Information ZPID; 2010. Available from: https://www.psychdata.de/index. php? main=search\&sub=browse \&id=fgjn 82 fr 19 \&lang $=$ eng . [Last accessed on 2019 Jun 19].

27. Ponizovsky PA. Cognitive Disorders and Somatic Anosognosia in Patients with Alcohol Dependence. The Author's Abstract of Doctoral Dissertation. Moscow: Moscow Research Institute of Psychiatry; 2007.

28. Baranova OV. Alcohol Anosognosia and its Overcoming in the Treatment of Patients With Alcoholism: Doctoral Dissertation. Moscow: The St. Petersburg Bekhterev Psychoneurological Research Institute; 2005. 